Tropical Journal of Pharmaceutical Research January 2019; 18 (1): 123-127

ISSN: 1596-5996 (print); 1596-9827 (electronic)

(c) Pharmacotherapy Group, Faculty of Pharmacy, University of Benin, Benin City, 300001 Nigeria.

\title{
Effect of recombinant human brain natriuretic peptide on myocardial enzymes and cardiac function after percutaneous coronary intervention in patients with acute myocardial infarction
}

\author{
Yuntao Cheng ${ }^{1,2}$, Guangxia Yang ${ }^{3}$, Yuansheng Tang1, Chuanfang Li $^{2}$, Meng \\ Zhang $^{2}$, Lianqun $\mathrm{Cui}^{1}$ \\ ${ }^{1}$ Department of Cardiology, Provincial Hospital Affiliated to Shandong University, Jinan, Shandong 250021, ${ }^{2}$ Department of \\ Cardiology, ${ }^{3}$ Respiratory Medicine Department, Affiliated Hospital of Jining Medical University, Jining, Shandong 272000, China \\ *For correspondence: Email: It1174@163.com
}

\begin{abstract}
Purpose: To study the effect of recombinant human brain natriuretic peptide rhBNP on myocardial enzymes and cardiac function following percutaneous coronary intervention (PCl) in acute myocardial infarction (AMI) subjects.

Methods: Patients with AMI (124 cases) subjected to PCl for 2 years were used as subjects in this investigation. Two groups of patients were used (62 patients per group). One group received rhBNP while the other group served as control. The patients consisted of 76 males and 48 females (mean age, $63.54 \pm 12.31$ years). The two groups of patients received $75 \mathrm{mg} / \mathrm{kg}$ body weight of clopidogrel orally and aspirin $(300 \mathrm{mg} / \mathrm{kg}) 2 \mathrm{~h}$ before PCl. The peaks of creatine kinase (CK), creatine kinase MB (CK$M B$ ), and the levels of troponin I (cTnl) were assayed at pre-determined intervals with an automated biochemical analyzer, and changes in the enzyme levels were recorded. Echocardiography (ECG) parameters were also measured.

Results: Lower peaks of CK, CK-MB and levels of CTnl were seen in rhBNP-treated patients, when compared with controls $(p<0.05)$. Total effectiveness was markedly higher in rhBNP-treated group than in control group $(p<0.05)$. Moreover, myocardial infarct size was significantly lower in rhBNP treatment group than in control group $(p<0.05)$.

Conclusion: Treatment with rhBNP before $\mathrm{PCl}$ in patients with $\mathrm{AMI}$ increases coronary blood flow, ameliorates perfusion injury, inhibits left ventricular remodeling, reduces myocardial cell necrosis, and improves cardiac function and prognosis.
\end{abstract}

Keywords: Recombinant human brain natriuretic peptide (rhBNP), Acute myocardial infarction, percutaneous coronary intervention, Myocardial enzymes, Cardiac function

\begin{abstract}
This is an Open Access article that uses a funding model which does not charge readers or their institutions for access and distributed under the terms of the Creative Commons Attribution License (http://creativecommons.org/licenses/by/4.0) and the Budapest Open Access Initiative (http://www.budapestopenaccessinitiative.org/read), which permit unrestricted use, distribution, and reproduction in any medium, provided the original work is properly credited.

Tropical Journal of Pharmaceutical Research is indexed by Science Citation Index (SciSearch), Scopus, International Pharmaceutical Abstract, Chemical Abstracts, Embase, Index Copernicus, EBSCO, African Index Medicus, JournalSeek, Journal Citation Reports/Science Edition, Directory of Open Access Journals (DOAJ), African Journal Online, Bioline International, Open-J-Gate and Pharmacy Abstracts
\end{abstract}

\section{INTRODUCTION}

Acute myocardial infarction (AMI) refers to myocardial necrosis caused by acute and persistent ischemia and hypoxia in coronary arteries. The most common clinical manifestation of $\mathrm{AMI}$ is angina pectoris. In Europe and the United States, about 1.5 million people suffer 
from myocardial infarction annually, and in China its incidence has gradually risen in recent years. At present, available treatment options for AMI include drug therapy, bone marrow mesenchymal stem cell (BMSCS) transplantation, and percutaneous coronary intervention (PCI) [1].

Clinically, $\mathrm{PCI}$ not only reduces the incidence of myocardial infarction, but also confers protection to the myocardium [2]. Although $\mathrm{PCl}$ is an effective procedure, direct and elective $\mathrm{PCl}$ come with some risk, because they may lead to distal thrombotic obstruction. Thus, the myocardial tissue may not achieve blood perfusion in the infarct area, which inevitably leads to different degrees of deterioration of cardiac functions in patients [3]. In a previous study, it was reported that some patients usually come down with heart failure after $\mathrm{PCl}[4]$.

Recombinant human brain natriuretic peptide (rhBNP) is a first-line drug for the treatment of AMI because it can significantly increase myocardial blood supply and coronary blood flow in patients with heart failure. This investigation was carried out to study the effect of rhBNP on myocardial enzymes and heart function after $\mathrm{PCl}$ in patients with AMI.

\section{EXPERIMENTAL}

\section{Patients and general information}

Patients with AMI (124 cases) subjected to PCl for two years were used as subjects in this investigation. The patients were randomly assigned to two groups of 62 patients each: patients treated with rhBNP and control group. The AMI subjects consisted of 76 men and 48 women (mean age $=63.54 \pm 12.31$ years) . Patients who met the criteria for AMI by World Health Organization (WHO) were selected. The exclusion parameters were: (1) patients who had cardiogenic shock, insufficient circulating blood volume, or other clinical conditions; (2) patients whose angiography results showed distal and proximal indicators of thrombolysis in myocardial infarction (TIMI) grade > 0; (3) patients who had liver, kidney, and heart diseases; (4) patients with a history of myocardial infarction; and (5) patients who were allergic to rhBNP. The patients signed written informed consent with their family members. Age, risk factors and time of onset were comparable between the two groups of patients.

This study received approval from Ethical Committee of Cardiology Department, Provincial Hospital Affiliated to Shandong University, Jinan,
Shandong (approval no. 20183143), and carried out in line with the guidelines of Helsinki Declaration of 1964, as amended [5].

\section{Treatment regimen}

The two groups of patients received $75 \mathrm{mg} / \mathrm{kg}$ of clopidogrel orally and aspirin (300 mg/kg) $2 \mathrm{~h}$ before PCI.

\section{Control group}

Immediately after the onset of symptoms, heart function was controlled in the patients by intravenous injection of nitroglycerin at doses based on hemodynamics and blood pressure.

\section{RhBNP treatment group}

Intravenous bolus dose of $1.5 \mu \mathrm{g} / \mathrm{kg}$ rhBNP was given within $90 \mathrm{sec}$ and the drip was controlled at a rate of 0.015 to $0.030 \mu \mathrm{g} / \mathrm{kg}$ min according to the patient's blood pressure and hemodynamics. The duration of treatment in the two groups was 7 days. During the course of treatment, antiplatelet drugs and blood lipid-lowering drugs were administered according to relevant guidelines based on the patient's clinical condition.

\section{Assessment indices}

Blood was drawn at intervals of $2 \mathrm{~h}$ after admission and 1 day after surgery, and at the end of the second day, blood was taken at intervals of $12 \mathrm{~h}$. The peaks of creatine kinase (CK), CK-MB, and the levels of troponin I (cTnl) were determined using an automated biochemical analyzer, and changes in the enzyme dynamics were recorded.

Echocardiography (ECG) was performed at 1, 4, and 12-week intervals after surgery, and the left ventricular end diastolic diameter (LVEDD), left ventricular ejection fraction (LVEF), stroke volume (SV), and left ventricular diastole were also measured, and their mean values taken.

\section{TIMI blood flow classification}

Grade $0=$ no perfusion; grade $\|=$ partial perfusion; and grade III = complete perfusion [6].

\section{Evaluation of efficacy}

This was determined based on Killip Grading Standard as follows: Level 2 and above = markedly effective; level 1 = improved; and level $0=$ ineffective. The total effectiveness was calculated using the formula: 
$\operatorname{TE}(\%)=\{(S+I) / 43\} 100$

where TE is total effectiveness; $S$ is significant effectiveness; / is improved effectiveness

\section{Statistical analysis}

The results are presented as mean \pm SEM, and were analyzed with SPSS version 20.0. Groups were compared with $t$-test. Quantitative data were compared between groups using $x^{2}$ test. Fisher's exact probability test was employed for analysis of TIMI grades after PCl. Statistical significance was fixed at $p<0.05$.

\section{RESULTS}

\section{Cardiac function after $\mathrm{PCI}$}

As shown in Table 1, significantly lower peaks of CK, CK-MB and lower CTnl levels were seen in the rhBNP-treated patients, relative to the control group $(p<0.05)$.

Table 1: Cardiac function after $\mathrm{PCl}$

\begin{tabular}{lccc}
\hline Group & $\begin{array}{c}\text { CK Peak } \\
(\mathbf{m o l} / \mathbf{l})\end{array}$ & $\begin{array}{c}\text { CK-MB } \\
\text { Peak } \\
(\mathbf{m o l} / \mathbf{l})\end{array}$ & $\begin{array}{c}\text { cTnl } \\
(\boldsymbol{\mu g} / \mathbf{l})\end{array}$ \\
\hline Control & $1586.64 \pm$ & $161.63 \pm$ & $15.67 \pm$ \\
& 847.52 & 82.45 & 2.40 \\
rhBNP & $1167.51 \pm$ & $112.73 \pm$ & $10.35 \pm$ \\
$X^{2}$ & $721.23^{*}$ & $65.42^{*}$ & $2.34^{\star}$ \\
\hline
\end{tabular}

\begin{tabular}{llll}
\hline$p$ & 0.0036 & 0.0004 & $<0.01$ \\
\hline
\end{tabular}

\section{Electrocardiography results}

There were no significant differences in LVEDD, LVEDV, LVESV, LVEF and SV between the control and rhBNP treatment groups 1 week after surgery $(p>0.05)$. At the end of 4 weeks postoperation, LVEDD, LVEDV and LVESV were markedly lower in the rhBNP-treated patients, relative to the control group $(p<0.05)$. However, LVEF and SV were significantly higher in rhBNPtreated patients than in control patients $(p<$ 0.05). At 12 weeks post-operation, LVEDD, LVEDV and LVESV were significantly lower in rhBNP-treated patients than in controls, but LVEF and SV in the rhBNP patients were significantly higher $(p<0.05$, Table 2$)$.

\section{Therapeutic effectiveness}

Table 3 shows that total effectiveness in the rhBNP treatment group was significantly higher than that in the control group $(p<0.05)$.

\section{Infarct-related angiography and myocardial infarction size}

As shown in Table 4, pre-operative TIMI grading and immediate post-operative TIMI in both groups were comparable $(p>0.05)$. However, rhBNP treatment brought about significant decrease in myocardial infarct size $(p<0.05)$.

Table 2: ECG parameters

\begin{tabular}{|c|c|c|c|c|c|}
\hline Group & LVEDD/mm & LVEDV/mm & LVESV /ml & LVEF $/ \%$ & $\mathrm{SV} / \mathrm{ml}$ \\
\hline \multicolumn{6}{|l|}{ Control } \\
\hline 1 post-surgery & $57.91 \pm 1.92$ & $79.19 \pm 6.24$ & $29.85 \pm 3.87$ & $48.20 \pm 5.13$ & $48.22 \pm 6.05$ \\
\hline 4 weeks post-surgery & $58.42 \pm 4.95$ & $80.19 \pm 6.03$ & $29.99 \pm 3.51$ & $51.62 \pm 5.31$ & $47.83 \pm 7.64$ \\
\hline $\begin{array}{l}12 \text { weeks post- } \\
\text { surgery }\end{array}$ & $57.74 \pm 2.92$ & $80.96 \pm 5.89$ & $29.89 \pm 3.47$ & $51.25 \pm 4.79$ & $50.72 \pm 4.78$ \\
\hline \multicolumn{6}{|l|}{ RhBNP treatment } \\
\hline 1 week post-surgery & $58.21 \pm 3.03$ & $81.28 \pm 6.43$ & $29.89 \pm 2.73$ & $49.87 \pm 4.35$ & $49.04 \pm 6.26$ \\
\hline 4 weeks post-surgery & $56.21 \pm 4.37^{-}$ & $72.76 \pm 4.82$ & $25.40 \pm 2.40^{\circ}$ & $55.19 \pm 5.94$ & $49.27 \pm 5.08$ \\
\hline $\begin{array}{l}12 \text { weeks post- } \\
\text { surgery }\end{array}$ & $55.02 \pm 2.34^{\#}$ & $71.25 \pm 4.35^{\#}$ & $24.98 \pm 2.37^{\#}$ & $56.08 \pm 5.86^{\#}$ & $53.91 \pm 5.53^{\#}$ \\
\hline
\end{tabular}

${ }^{\star} P<0.05$, relative to control; ${ }^{\#} p<0.01$, relative to levels at same time point

Table 3: Therapeutic efficacy ( $N, \%)$

\begin{tabular}{lcccc}
\hline Group & Significant effect & Improved & Ineffective & Overall efficacy \\
\hline Control & $24(38.71)$ & $21(33.87)$ & $17(27.42)$ & $45(72.58)$ \\
RhBNP & $33(53.22)$ & $23(37.10)$ & $6(9.68)$ & $56(90.32)^{*}$ \\
$X^{2}$ & & & & 6.4589 \\
$P$-value & & & & 0.0110 \\
\hline${ }^{*} P<0.05$, relative to control group & & &
\end{tabular}


Table 4: Infarct-related angiography and myocardial infarction size (n, \%)

\begin{tabular}{|c|c|c|c|c|}
\hline Parameter & $\begin{array}{l}\text { Control } \\
(n=62)\end{array}$ & $\begin{array}{l}\text { rhBNP-treated } \\
(n=62)\end{array}$ & $t / x^{2}$ & $P$-value \\
\hline \multicolumn{5}{|l|}{$\begin{array}{l}\text { Preoperative TIMI } \\
\text { classification (grade) }\end{array}$} \\
\hline 0 & $47(75.81)$ & $50(80.65)$ & 0.4261 & 0.5139 \\
\hline I & $11(17.74)$ & $9(14.52)$ & 0.2385 & 0.6253 \\
\hline II & $4(6.45)$ & $3(4.84)$ & 0.0000 & 1.0000 \\
\hline \multicolumn{5}{|l|}{$\begin{array}{l}\text { Immediately after surgery } \\
\text { TIMI (case) }\end{array}$} \\
\hline I & $1(1.61)$ & $0(0.00)$ & - & 0.6336 \\
\hline II & $6(9.68)$ & $4(6.45)$ & 0.4351 & 0.5095 \\
\hline III & $55(88.71)$ & $58(93.55)$ & 0.8978 & 0.3434 \\
\hline $\begin{array}{l}\text { Myocardial infarct size } \\
\left(\mathrm{cm}^{2}\right)\end{array}$ & $8.72 \pm 2.15$ & $7.75 \pm 1.38^{*}$ & 37.4871 & $<0.01$ \\
\hline
\end{tabular}

\section{DISCUSSION}

Acute myocardial infarction (AMI), a critical condition caused by the rupture of vascular plaque, causes thrombosis which leads to acute occlusion of blood vessels. The incidence, mortality and disability caused by AMI are on the increase, with age, history of diabetes, systolic blood pressure, left ventricular ejection fraction, and myocardial enzymes as risk factors associated with complications of the disease [7]. Creatine kinase (CK) and CK-MB are myocardial enzymes which reflect myocardial damage. The activities of these enzymes increase to varying degrees when myocardial damage or necrosis occurs. Clinically, CK and CK-MB are used as common indicators for monitoring the development of AMI.

Troponin I (cTnl) is one of the three subunits of cardiac and skeletal muscle contractile regulatory proteins (troponin), and it is often used as an indicator in the diagnosis of myocarditis [8]. Direct $\mathrm{PCl}$ in the treatment of $\mathrm{AMI}$ can reduce or slow down recurrent myocardial ischemia, recurrent myocardial infarction, stroke and death. When compared to drugs used in perfusion therapy, direct $\mathrm{PCl}$ can reduce the mortality rate of AMI to 4 - $6 \%$ [9]. Brain natriuretic peptide (BNP) is produced in the ventricle and it serves as a quantitative marker of heart failure, reflecting left ventricular systolic dysfunction, right ventricular diastolic dysfunction, valvular dysfunction, and right ventricular dysfunction [9].

RhBNP is a synthetic endogenous hormone with the same amino acid sequence as BNP in dilated blood vessels. It exerts the same biological effect as BNP in protecting the heart [10].

In the present study, the peaks of CK, CK-MB and levels of cTnl in the rhBNP-treated patients were significantly decreased. The LVEDD, LVEDV, LVESV, LVEF and SV were comparable between the control and rhBNP treatment group at 1 week after surgery. At the end of 4 weeks post-operation, LVEDD, LVEDV and LVESV were significantly lower in the rhBNP treatment group than in the control group.

However, the LVEF and SV in the rhBNP treatment group were significantly higher than those in the control group. At 12 weeks postoperation, LVEDD, LVEDV and LVESV were significantly decreased in the rhBNP-treated patients, while LVEF and SV were markedly increased in the patients treated with rhBNP. It has been suggested that rhBNP can significantly improve myocardial injury caused by ischemia and hypoxia, probably by increasing coronary blood flow, reducing resistance to circulation, delaying or preventing ventricular remodeling, and preventing the expansion of myocardial infarct size, thus protecting heart function [11]. Similar findings have been reported in other studies [12,13].

Treatment with rhBNP resulted in markedly higher clinical effectiveness, when compared with patients who were not exposed to rhBNP. This indicates that early treatment with rhBNP is very effective in patients undergoing $\mathrm{PCl}$. The myocardial infarct size in the rhBNP-treated patients was markedly decreased, when compared with that in the control group. These results demonstrate that rhBNP inhibits left ventricular myocardial remodeling after an AMI event, which is in agreement with earlier findings [14]. It is possible that rhBNP may prevent and improve the level of ventricular remodeling by inhibiting growth factors and the proliferation, differentiation and protoplast synthesis of cardiac fibroblasts. In a previous study, it was reported that early use of rhBNP in patients with AMI can 
significantly reduce myocardial cell necrosis, improve left ventricular remodeling, and improve cardiac function [15].

\section{Limitations of the study}

This research was followed up for only 12 weeks. Thus, long-term effectiveness of the treatment is unclear.

\section{CONCLUSION}

Treatment with rhBNP before $\mathrm{PCl}$ in patients with AMI improves cardiac function and prognosis.

\section{DECLARATIONS}

\section{Conflict of Interest}

No conflict of interest associated with this work.

\section{Contribution of Authors}

We declare that this work was done by the author(s) named in this article and all liabilities pertaining to claims relating to the content of this article will be borne by the authors. All authors read and approved the manuscript for publication. Lianqun Cui conceived and designed the study. Yuntao Cheng, Guangxia Yang, Yuansheng Tang, Chuanfang Li, Meng Zhang and Lianqun Cui collected and analyzed the data. Yuntao Cheng wrote the manuscript.

\section{REFERENCES}

1. Zhao Y. Progress of Treatment of Acute Myocardial Infarction. J Math Med 2016; 29(4): 19-22.

2. Wan N, Xia H. Efficacy of rhBNP for heart failure after acute myocardial infarction: meta-analysis. Occup Health 2015; 31(2): 221-224.

3. Liu HW, Wang $X Z, M a Y Y$, Jing $Q M, X U K$, Wang $G$, Guan SY, Zhao $X$, Deng J, Han YL. Clinical effect of selective thrombus aspiration during primary percutaneous coronary intervention in patients with STsegment elevation myocardial infarction. Med J Chin People's Liberation Army 2015; 40(4): 271-274.

4. Zheng ZD, Cheng CL, Qu CH, Zhu JM, Zhao CL, Qian $X X$, Chen $L$. Clinical effect of recombinant human brain natriuretic peptide combined with levosimendan on acute myocardial infarction complicated by heart failure. Chin J Geriatri 2015; 34(11): 1231-1234.

5. World Health Organization. Declaration of Helsinki. Br Med J 1996; 313(7070): 1448-1449.

6. Liu YN. Recombinant human brain natriuretic peptide in the treatment of acute myocardial infarction complicated with acute left heart failure. Chin $J$ Integr Med Cardio/Cerebrovasc Dis 2013; 11(9): 1136-1137.

7. Zhang XM, Hu YZ, Chen XX, Wang JF. Analysis of risk factors for hospitalization death in patients with acute myocardial infarction. Guangdong Med J 2013; 34(2): 260-263.

8. $X u Y$, Yang $X J$, Zhang $G X$, You DH, Liu B, Gong $Y$. Clinical significance of detection of troponin and creatine kinase isoenzyme in the diagnosis of acute myocardial infarction. Chin J Lab Diagn 2015; (3): 443-444

9. Wei $P, F U$, Tao ZQ, Han B, Zhang YG, Huang YJ, Ling $L$, Yang XJ. Relationship between B-type natriuretic peptide and short-term prognosis in nondiabetic patients with ST-segment elevation myocardial infarction. Eur Rev Med Pharmacol Sci 2014; (3): 336-338.

10. Huo XF. Therapeutic effect of rhBNP combined with metoprolol on chronic heart failure and its effect on BNP and cardiac function. Chronic Pathematol J 2018; (2): 132-138.

11. Cao DL, Han L, Ni J, Wang ZQ. Effects of recombinant human brain natriuretic peptide on serum $C K-M B$ and $\mathrm{Tnl}$ in patients with acute myocardial infarction accompanied by heart failure. J Clin Med Pract 2014; 18(23): 14-16.

12. Meng $X J$, Li XG, Yang HM. Influence of recombinant human brain natriuretic peptide on the prognosis of patients with anterior wall acute myocardial infarction and heart failure after thrombolysis therapy. Chin J Crit Care Med 2013; 33(5): 436-439.

13. Cheng J. Effect of recombinant human brain natriuretic peptide on myocardial perfusion in patients with acute myocardial infarction after $\mathrm{PCl}$. Chin $\mathrm{J}$ Integr Med Cardio/Cerebrovasc Dis 2017; (20): 2581-2583.

14. Hu GX, Lin PX, Chang J, Wang F, Yan XL, Li LH. Effect of intracoronary injection of recombinant human brain natriuretic peptide on cardiac function in patients with acute myocardial infarction undergoing percutaneous coronary intervention. J Clin Cardiol 2013; (5): 350-353.

15. Zhang KL, Liu XK. Effect of Recombinant Human Brain Natriuretic Peptide on Outcomes of Patients with Acute Anterior Myocardial Infarction Receiving Rescue Percutaneous Coronary Intervention. J Med Res 2016; 45(7): 163-166. 